\title{
Cybersex: Advantages And Disadvantages
}

\author{
${ }^{1}$ Grace TanimoonwoFasugba-IdowuAnd ${ }^{2}$ Siti Aishah Hassan \\ ${ }^{1,2}$ University Putra Malaysia. Malaysia.
}

\begin{abstract}
Theavailability, anonymity and accessibility of the Internet have made the compulsive behavior of cybersex and cyber affairs more common in America and the world. The Internet has enabled people to fulfill their sexual fantasies and to share the same with people in different parts of the world without having to experience the physical consequences of the relationship. This behavior has long been debated to be a case of sexual infidelity.

The available literature that discusses the advantages and disadvantages of cybersex is inclined towards the perception that the activity has more significant cons than it does the pros. The disadvantages (and possible advantages) of cyber-sexual activity can be comfortably divided into three categories with moral, social and religious implications. However, on all levels, the behavior has more negative impacts than positive ones, most of which take a lot of time, energy and resources to reverse.

Personality theories can be used to understand abnormal sexual behavior. With personality theories, solving the problems that arise out of cybersex activities for individuals of different ages and marital status becomes easier because of a traceable chain of cause and effect events. The extent to which personality and sexual abnormality are related is debatable but research shows that there is a significant correlation. The significance of this study in academics and personal use is related to the need for insight and regenerative production of data that is related to it.
\end{abstract}

Keywords: Cybersex, Cyber-affairs, Internet, sexual/sexually, Marriage, relationship.

\section{Introduction}

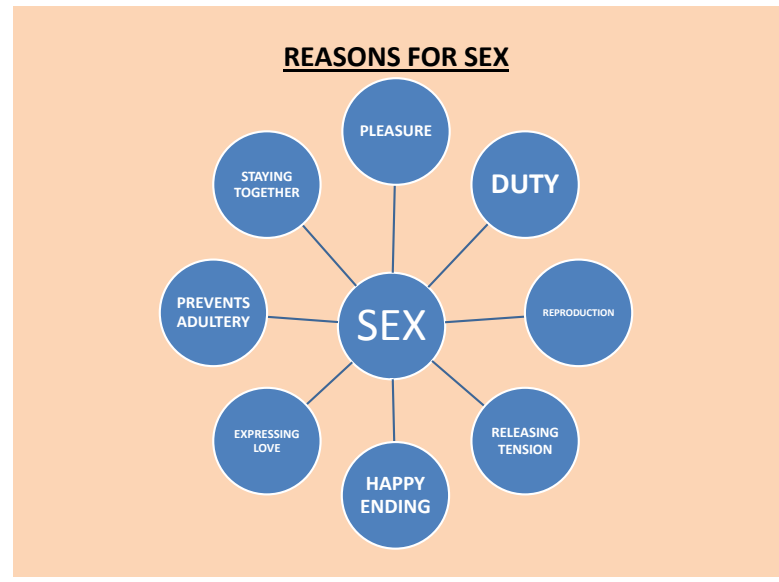

Cybersex is the engagement of Internet users in sexual conversation and physical participation to the level where it is possible to satisfy the urge for sexual pleasure on personal computers or other Internet enabled gadgets (Daneback et al., 2005). Daneback et al. Explain that the interaction may be between two or multiple people and may include or exclude masturbation (2005). Cybersex has taken many forms over time as technology continues to be accessible and affordable for all and as the Internet technology continues to play a major part of most careers. One of the phenomena that have come out of cybersex is the 'cyber-affair'.

Cyber-affairs are any romantic or sexually oriented relationships initiated via online communication and maintained predominantly over electronic conversations that occur in virtual communities (Young et al., 2000). This kind of relationship can be continuous between two or more people or it may be random instances of erotic chat room encounters between or among strangers (Young et al., 2000). Cybersex activities are mostly categorized as cases of infidelity and sexual perversion. 


\section{Literature Review}

Much of the literature on the subject of cybersex is inclined towards the debates of its advantages and disadvantages; its moral, social and religious implications; and the psychological or behavioral theories that relate to the participation and participants in the audio-visual sexual activity. The trends and emerging issues surrounding cybersex are also a popular subject among those that engage cybersex as a topic of academic literature. Demographically, the number of people engaged in online sexual activities is rising as the Internet continues to grow and develop all over the world (Daneback et al., 2005).

Daneback et al. (2005) conducted an Internet study on cybersex participants during an era referred to by earlier authors as the next sexual revolution (Daneback et al., 2005).

The behavioral effects of cybersex are both intrapersonal and interpersonal. On an interpersonal level the most attention is given to the issue of sexual addiction and its relation to the Internet abuse (Griffiths, 2012).

This debatable factor has been contended on a social, conventional, scientific and moral level, each with its own implication on the perception of the different researchers and authors on the participants of cybersex (Griffiths, 2012). Griffiths explains that salience, mood modification, tolerance, withdrawal symptoms and relapse are the common characteristics of individuals whose behavior is partly dominated by exposure to sexual content (Griffiths, 2012).

The interpersonal effects of being addicted to cybersex occur when the habit becomes so pronounced in the life of the Internet user that it affects the way that he/she interacts with other individuals in the community.

The first relationship that suffers harm when cybersex or any other form of sexual 'addiction' becomes habitual is the intimate marriage relationship (Brady, 2007). As one becomes exposed, addicted and aroused by harder and more graphic forms of sexual interactions, their sexual demands become more than most average partners are willing or able to deliver causing a strain in the relationship (Brady, 2007). The habit of engaging in cybersex takes more practical forms that damage the social relationships of individuals when they lose their self control and expose themselves to promiscuity, dangerous sexual interactions and guilty conscience (Brady, 2007). All these habits inhibits the normal interaction of individuals on a social level.The moral risk of becoming a partaker of cybersex in the conventional world is generally the social exposure of possessing the aforementioned negative character traits.

Clergy and other leaders easily lose their moral high ground and their ability to inspire using their leadership positions when their engagement in questionable sexual activities becomes exposed to the public. The urge to watch sexual content on the Internet becomes unmanageable leading to biological adjustments that demand the clergy's habitual exposure to sexual content (Laaser \& Gregoire, 2003). As the people that engage in cybersex become more tolerant of the activity in terms of level of arousal per activity, their mood becomes a function of how much and which kinds of cybersex activity they have engaged in within the prevailing few hours (Laaser \& Gregoire, 2003). The anonymous nature of the Internet is perhaps the most tempting feature that causes leaders to be part of the virtual community that engages in unrestricted sexual activities (Laaser \& Gregoire, 2003).

Delmonico and Griffin agree that the effects of cybersex are all negative in the long run. The authors state that exposure to cybersex leads to varied levels of pain, shame and consequences depending on the level of individual engage in the compulsive behavior (Delmonico \& Griffin). Addiction to cybersex is uneconomical, not just because of the amount of money that is spent on the adventures of sexual fantasies, but also because of the amount of time that 'addicts' engage in sexual fantasies and sexual behavior (Delmonico \& Griffin). The amount of energy that goes into concealing the habit of sexual compulsiveness on the Internet causes the relationships of individuals to their sexual, spiritual or other relatives to become tense, which eventually breaks into unsuccessful relationships (Delmonico \& Griffin).

The cost of engaging in cybersex is more than just financial. Cybersex leads to broken relationships such as marriage in the form of divorce, separation and emotional alienation (Schneider, 2000). The financial costs of the different ways of alienation are followed by emotional costs, psychological costs and poor performance on other important issues. The work done by Schneider is a product of a qualitative research conducted via e-mail engagements with therapists and people affected by cyber sex.

\section{Conceptual Framework}

The concepts in this research paper are subject to the moral, social and religious perspectives of different individuals as a subject of experience and study. It is within these categories that the literature review was selected. The concepts that are within the research are those that have been proven over the years in observable cause and effect relationships of cybersex and social, moral or religious serenity in the society. The basic perspectives of the individuals cited for concepts in the research are that the activity of cybersex in all its forms is more disadvantageous than it is advantageous to social, moral and religious life. 


\section{Morally}

Cybersex is the function of using the physical senses such as sight and touch heightened by imagination to take advantage of the anonymity, availability and interactivity of the Internet to derive sexual pleasure (Ben-Ze'ev, 2004). Imagination may lead directly to real sense interactions that may have negative impacts on the actions that individuals take (Ben-Ze'ev, 2004). The nature of cybersex as a function of imagination does not make the activity immune to criticism because the activity has some practical implications (Ben-Ze'ev, 2004). Ben-Ze'ev (2004) states that cybersex has all the basic characteristics of actual sexual activity except for the physical interaction (although there may be physical action) which makes it a kind of infidelity.

Much debate goes into the morality or the immorality of cybersex because there are different levels of moral standards for different individuals and communities. Apart from excessive liberal groups that allow for promiscuity to prevail among other unconventional practices in relationships, the norm for sexual relationships is exclusivity. Once two people are in a sexual relationship, then they are expected by their partners and by the community that holds them responsible for their actions (family, friends, and so on) to refrain from sexual contact with other partners on a verbal, physical and mental level at all times. The elements of orgasm and intimacy are typical of sexual relationships and they are present in cybersex (Ben-Ze'ev, 2004). This makes the participation of any individual in cybersex an immoral activity because it leads to lies, deception and corruption.

The immorality of cybersex is heightened by the limits within which the activity can be initiated and maintained. It is not uncommon for female children below the age of fifteen to be engaged in virtual sexual relationships with men much older than them. When cybersex turns into habitual exposure to pornography then the human mind becomes corrupted beyond acceptable moral levels. The perversion that is caused by continuous exposure to cybersex makes men and women have sexual fantasies about children which lead to child molestation and sexual exploitation of children (Lanning, 2010).

Lanning (2010) suggests that engaging in sexual activity with children over the cyberspace is exposing children to potential danger and harm which is as morally unacceptable as child prostitution although their legal status may differ. The society and all concerned parties such as parents and guardians find cybersex with children an immoral activity (Lanning, 2010).

Cyberspace has created a platform for children to learn sexual information that should be out of their reach until they are adults. Indirect victimization is the effect of cyber communication that is sexual in nature that occurs between adults and children (Lanning, 2010). Cybersex is morally unacceptable on a general scale because all adults with fully functional moral and mental faculties would not like to have their children or other people's children exposed to the same (Lanning, 2010).

\section{Socially}

The first disadvantage of engaging in cybersex on a social level is the deterioration of any sexual relationship and satisfaction derived from sexual and emotional contact between the people in the relationship (Daneback et al., 2005). Daneback et al. (2005) explain that online affairs turn into offline affairs that cause the breakdown of the family unit which spirals into other negative social effects on both the relating adults and any children they may have.(Daneback et al., 2005). Research has shown that the social effect of cybersex attachment is a leading cause of separation and divorce for affected couples (Callan et al., 2010). Some of them have negative impacts on the social status of the participants. The kinds of expectations that addicts of sexual material in the cyberspace have about their partners, the beliefs that are planted in the minds of individuals who are continually exposed to cybersex, unconventional sexual practices and their attitudes about love and intimacy make them social aliens (Callan et al., 2010).

When one cannot control the outcomes of his/her activities as far as his/her children are concerned, then he/she loses self-esteem which causes a wide range of other social problems. Guilt, low self-esteem and criminal activities of sexual origin make individuals function in a more or less strange manner within social circles (Callan et al., 2010).

When one is exposed to habitual viewing of pornographic material, then they may lose the association of friends and acquaintances who detest the habit, and gain little support from their close relatives. This may cause depression and other conditions that arise because of alienation. This is without mentioning the risks that exist on a social level in terms of health for people who change online interaction into offline interaction.

Social effects of cybersex not only influence the individuals that engage in it but their partners and children as well (Goldberg. 2012). The children and partners of people that engage in cybersex become socially and psychologically affected to the point that they even need therapy (Goldberg. 2012). He explicitly quotes Young (2001) stating that recreational and pathological users of cybersex develop habits that affect their children and families. The importance of recreation as the only advantage of cybersex fades to the back when other important affairs surface. 


\section{Religiously}

Different religions have different regulations concerning sexual activity. Most of the regulations in religion (considering the world's most common religions such as Christianity, Islam, and Judaism) can be used to determine the advantages and disadvantages of cybersex. The common factor in all religions that is not cults is that the precepts emphasize correct thought as the start point for correct action. The religions also prohibit most unconventional and extramarital activities which are encouraged by the use of cybersex. They outlaw adultery, fornication and other sexual malpractices both in word and in action.

The effects of cybersex on a social and moral level make the activity illicit in religious terms because it leads to fornication, adultery, paedophilia and other forms of sexual sin. The Old Testament of the Bible is relatively common to the three religions that have been mentioned above. These sins are explicitly outlawed in different parts of the Old Testament. The Ten Commandments also explicitly outlaw the kinds of sexual activities that cybersex encourages (Exodus 20).This is also supported in various places in the New Testament $\left(1^{\text {st }}\right.$ Corinthians 6:9-10, $2^{\text {nd }}$ Timothy 2:22). It is common for religious people to state that they can use cybersex to suppress the urge to sin, but these people neglect the truth about the human mind as the chief trigger of human action.

In the Quran it is explicitly stated that the engagement of men and women in adulterous activities is sinful because it is foul and improper (17:32). On the grounds that engaging in cybersex activities makes the participant lustful for vile things that lead to adultery, it is indirectly outlawed in Islam. In another section of the Quran it is stated that men should not go near things that are shameful whether in open or in secret (6:151). This clearly includes activities such as cybersex.

\section{Personality Theories Associated with Abnormal Sexual behaviors}

Differences in human sexual behavior can be attributed to differences in human personalities according to the study conducted by Eysenck in 1976 (Barnes et al.1984). When comparing extroverts to introverts, the author suggests that the extroverts are more likely to engage in variety of sexual abnormalities than introverts (Barnes et al.). This suggests that the more outgoing person would more likely experiment and research on sex which may easily lead them to cybersex and its effects. Sexuality of abnormal nature that triggers people to have sex with children or to be obsessed with sexual activity within the cyber space is associated with psychotic behavior (Barnes et al.1984).

The people that engage in abnormal sexual activities may be expressing their emotional and psychological needs for release. (Barnes et al.1984). These kinds of people are theorized to be more interested in impersonal sex or aggressive sex (Barnes et al.1984). This suggests that the adventure and excitement that is present in cybersex would be thrilling to psychotic people who may go ahead and express the ideas put in their head during the activity in their offline lives. In extreme cases interacting with a psychotic sexual adventurer can be a dangerous encounter. The psychological state of a human being at a time may cause them to engage in sexual behavior that they otherwise would not.

\section{Advantages}

On the contrary, some people believe that cybersex can be used as a compliment to an existing sexual relationship, a safe method of sexual experimentation and an alternative for people with 'unique' sexuality (Daneback et al.2005); This enables socially shy people, people with low self-esteem, people that are not in sexual relationships and other social misfits to derive anonymous sexual pleasure without judgment being passed on to them.

Cybersex allows real life spouses who are geographically separated to continue to be sexually intimate with the use of their imaginations. It can function to sustain the sexual dimension of a relationship in which the partners do not see each other frequently face to face, due to work or other factors.

Also, it can allow partners to work out problems that they have in their sex life that they feel uncomfortable discussing it when facing each other or taking it to a marriage Counselor. In addition, people with long-term ailments (including HIV) can engage in cybersex as a way to safely achieve sexual gratification without putting their partners at any health risks. Some people also consider cybersex a physically safe way for young people, such as teenagers to experiment with their sexual thoughts and emotion, more so, it is financially less demanding on the Internet than in real life. These are among some of the perceived advantages of cybersex.

\section{Cybersex and Marital Dysfunction}

As stated earlier, excessive compulsive behavior in sexual activity is a major cause of broken relationships. One of the most fundamental units that may be destroyed as a result of an adult's obsession with cybersex is the family unit. In case one partner is found out or admits that they have a problem with cybersex, Marital Counselling may be implemented as a method of salvaging the relationship. There are many and 
frequent cases of marital counselling becoming a necessary factor in relationships as a result of one or both partners being addicted to cybersex or other forms of sexual weaknesses (Mark 2006).

The available literature that discusses the issue of Marital Counselling as a means of solving marital problems suggests that when applied properly, the activity leads to some level of healing for the couple (Mark 2006). Healing in this case refers to the restoration of trust, improved personal and interpersonal awareness, forgiveness, boundary establishment, improved intimacy, image restoration and improved self control (Mark 2006).

\section{Significance of the Research}

$>$ The significance of this research is that by defining and understanding cybersex, the audience may comprehend that the demerits of Cybersex are more and weightier than the perceived merits of the same.

$>$ The research is also useful because it shows that people that are obsessed with cybersex can be helped to overcome the habit through therapy and strong support systems.

$>$ Rimington (2008) correctly explains that by understanding the moral, social and religious implications of cybersex individuals can realize that the perceived advantages of cybersex are short term pleasures that may lead to deeper emotional, physical and psychological problems.

$>$ In the spirit of empathy this study also enables its audience to understand that the people are 'addicted' to sex in cyberspace are in need of help rather than judgment and alienation.

> Although it may be self-inflicted, the behavior of obsessive compulsive addiction to cybersex is harmful and those who engage in it should be helped to recover rather than being labelled outcasts.

$>$ The paper is also a basis for future research because it can be used as a reference source.

\section{Conclusion}

There are more disadvantages than advantages of engaging in cybersex. Cybersex is habitual and it is advisable to refrain rather than experiment, open up to partners in relationships, rather than keep the habit a secret (Jones, 2008). There are healthier alternatives of stress relief and stress management that have less detrimental effects (Jones, 2008). These are the options that individuals should be exposed to before they are too deep in the compulsive obsessive cybersex activities. Finallyif marital Counselling on couples that are losing their relationship because of cybersex is possible, then it is a worthwhile investment of time as it may prevent family breakdowns.

\section{References}

[1]. Barnes, G. E., Malamuth, N. M. \& Check, J. V. P. (1984). Personality and Sexuality. Personality Individual Differences, 5 (2), 159172. Retrieved 25 Sep.2012,Fromhttp://www. personality- project.org/revelle/publications/revelle.issid.07.pdf.

[2]. Ben-Ze'ev, AEmotions and Morality in Computer-mediated Romantic Relationships. 25 Sept.,2012,Fromhttp://emotionresearch.net/projects/humaine/ws/wp10/presentation-materials/AaronBenZeev-wp10wsMoralityOnlineRelationships-final.pdf

[3]. Brady, E. (2007). Cybersex. Retrieved 25 http://elainebrady.com/docs/Cyber_Sex.pdf

[4]. Callan, S., Benson, H., Coward, S., Davis, H., Gill, M., Grant H., Percival, D. \&

[5]. Daneback, K., Cooper, A.,\&Mansson, S. (2005). An Internet Study of Cybersex Participants. Archives of Sexual Behavior, 34 (3), 321-328. Retrieved 25 Sep., 2012,

[6]. http://www.hawaii.edu/hivandaids/An_Internet_Study_of_Cybersex_Participants.pdf.

[7]. Delmonico, D. L. \& Griffin, E. Cybersex Unhooked: Understanding and Managing Compulsive Online Sexual Behavior. Retrieved 25 Sep.,2012,Fromhttp://www.internetbehavior.com/pdf/Cybersex\%20Unhooked\%20article.pdf

[8]. Edwards, D. (2011). Getting Help for Cybersex Addiction.Retrieved 25 Sep., 2012, From https://www.achievesolutions.net/achievesolutions/en/Content.do? contentId=10425

[9]. Griffiths, M. Sex Addiction on the Internet. Retrieved 25 Sep., 2012, From http://scholar.lib.vt.edu/theses/available/etd04262004142455/unrestricted/PeterDGoldbergThesis.pdf

[10]. Goldberg, D. P. An Explanatory Study about the Impacts that Cybersex (The Use of the Internetfor Sexual Purposes) is Having on Families and the Practices of Marriage and Family Therapists. Retrieved 25 Sep., 2012, From http://scholar.lib.vt.edu/theses/available/etd- 04262004142455/unrestricted/PeterDGoldberg/Thesis/pdf

[11]. Heim, A. \& Westen, D. (2004). Theories of Personality and Personality Disorders. Department of Psychiatry and Behavioral Sciences and Department of Psychology Emory University.

[12]. Retrieved 25 Sep., Fromhttp://www.psychsystems.net/Publications/2005/17.\%20theories\%20of\%

[13]. 20personality $\% 20$ and $\% 20$ personality $\% 20$ disorders_Heim_textbook $\% 20$ of $\% 20$ pers $\% 20$ disorders $\% 2$

[14]. Jones, D. (2008). Cyber Sex for Nuts. Excerpt from Sex Prisoners. Retrieved 25 Sep., 2012,From http://www.whattheproblemis.com/documents/cb/cb_cybersex.pdfLaaser, M. R. \& Gregoire, J. L (2003). Pastors and Cybersex $\begin{array}{lllllll}\text { Addiction. Sexual and Relationship Therapy,18 (3), 396-407. Retrieved 25 Sep., 2012, From } & \end{array}$ http://www.thehopeofsurvivors.com/pdf_files/Pastors_Cybersex_Addiction.pdf

[15]. Lanning, K. V. (2010). Child Molesters: A Behavioral Analysis. National Centre for Missing \& Exploited Children.Retrieved 25 Sep2012,

Fromhttp://www.missingkids.com/en US/publications/NC70.pdf.02005.pdfhttp://www.thehopeofsurvivors.com/pdf_files/Pastors_C ybersex_Addiction.pdf 
[16]. Mark, B. H. (2006). Sexual Addiction and Marriage and Family therapy: Facilitating Individual and Relationship Healing through

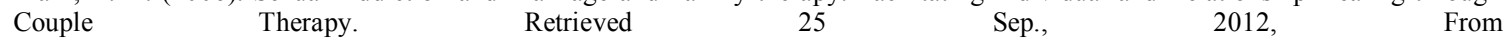
http://scholar.lib.vt.edu/theses/available/etd04272009102213/unrestricted/MarkBirdDissertation

[17]. Rimington, D. D. (2008). Examining the Perceived Benefits for Engaging in Cybersex Behavior among College Students. Retrieved 25 Sep., 2012,From http://digitalcommons.usu.edu/cgi/viewcontent.cgi

[18]. Schneider J. P. (2000). Effects of cybersex addiction on the family: Results of a survey. Sexual Addiction and Compulsivity, 7, 3158. Retrieved 25 Sep., 2012,

[19]. The Holy Bible. Exodus 20: $13-17 \cdot 1^{\text {st }}$ Corinthians 6:9-10

[20]. The Holy Quran. 6:151-7:32. 